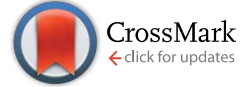

Cite this: RSC Adv., 2017, 7, 17497

Received 10th February 2017

Accepted 12th March 2017

DOI: 10.1039/c7ra01709j

rsc.li/rsc-advances

\section{1-Alkyl-3-methylimidazolium 4-organyloxy- 2,3,5,6-tetrafluorophenyltrifluoroborates as a new platform for ionic liquids with specific properties $\uparrow$}

\author{
Sergey A. Prikhod'ko, ${ }^{a}$ Anton Yu. Shabalin, ${ }^{a}$ Vadim V. Bardin, ${ }^{b}$ llia V. Eltsov, ${ }^{c}$ \\ Inna K. Shundrina, ${ }^{b}$ Valentin N. Parmon ${ }^{a}$ and Nicolay Yu. Adonin ${ }^{\star a}$
}

A new synthetic platform for ionic liquids (ILs) with specific properties was suggested based on the polyfluorophenyltrifluoroborate anions, $\mathrm{Q}\left[4-\mathrm{XC}_{6} \mathrm{~F}_{4} \mathrm{BF}_{3}\right](\mathrm{X}=\mathrm{F}$, RO). Convenient preparative approaches to these ILs including the ones with chiral counteranions were developed. The dependence of physicochemical properties of ILs on the nature of substituents in the fluorinated ring was studied.

\section{Introduction}

It is known that the properties of molten salt systems are mainly determined by the Coulomb interactions between the cations and anions ${ }^{1}$ which are responsible for the formation of ion pairs and higher ionic clusters that shorten the interionic distance and decrease the coordination number of ions. As a result, the volume increases during melting and forming "free" volume. ${ }^{2}$ According to the current definitions, ionic liquids (ILs) are salts in the liquid state at temperatures below $100{ }^{\circ} \mathrm{C}$; they are a special kind of molten salt system. ${ }^{3}$ Unique physical and chemical properties of ILs are tunable upon changing the anion and cation and have determined application areas of ionic liquids, including electrochemistry, ${ }^{4-7}$ organic synthesis, ${ }^{8-16}$ liquid/liquid extraction, ${ }^{17-19}$ catalysis, ${ }^{20-26}$ and nanostructured materials. ${ }^{27-34}$ There are several features which make ILs different from the conventional molten salts. ${ }^{35}$ First, at least one of the ions of the ionic liquid must possess a molecular asymmetry. This prevents the strong charge ordering which promotes the system to crystallize in the case of conventional molten salts. ${ }^{36}$ Second, the delocalization of the positive and negative charges affects directly the energy of the Coulomb interactions of the cations and anions. Addition to the Coulomb interactions is a network of hydrogen bonds between the cations and anions inducing their structural orientation. ${ }^{2}$

The anions with delocalized negative charge in combination with 1,3-dialkylimidazolium cations produce low-viscous and

${ }^{a} G$. K. Boreskov Institute of Catalysis SB RAS, Lavrent'ev Ave., 5, 630090 Novosibirsk, Russia.E-mail: adonin@catalysis.ru; Fax: +7 3833308056

${ }^{b} N$. N. Vorozhtsov Novosibirsk Institute of Organic Chemistry SB RAS, Lavrent'ev Ave., 9, 630090 Novosibirsk, Russia

${ }^{c}$ Novosibirsk State University, Pirogova Str., 2, 630090 Novosibirsk, Russia

$\dagger$ Electronic supplementary information (ESI) available: Spectral information on all ionic liquids and results of viscosity measurements. See DOI: 10.1039/c7ra01709j poorly water-miscible ionic liquids. ${ }^{18,37-44}$ 1,3-Dialkylimidazolium salts $\left(\mathrm{RR}^{\prime} \mathrm{Im}^{+} \mathrm{X}^{-}\right)$are the most stable and conductive among the known ionic liquids., ${ }^{70,44-49}$ One of these salts are corresponding tetrafluoroborates, $\mathrm{Q}\left[\mathrm{BF}_{4}\right] .^{50}$ Many researchers studied their properties. The main drawback of ILs based on tetrafluoroborate anion is their limited hydrolytic stability. ${ }^{3}$ The hydrolytic stability of ILs based on fluoroborates salts can be improved by substituting of perfluoroalkyl $^{39,51-54}$ or cyano ${ }^{37}$ group for one or more fluorine atoms in the $\mathrm{BF}_{4}$ anion. The first attempt to produce ionic liquids with an arylboron-containing anion, phenyltrifluoroborate, is reported elsewhere. ${ }^{55}$ This approach was used for preparing a series of ionic liquids with interesting properties..$^{36,37,56-60}$

There are only scarce literature data on ionic liquids with aromatic anions; ${ }^{35}$ the salts of arylcarboxylic and arylsulfonic acids are only known. ${ }^{61-63}$ However, ILs with aryl-containing counteranion are expected to feature many interesting properties due to more efficient delocalization of the negative charge and a number of specific interactions of the aromatic ring.,60-66

Despite the progress in preparing functional ILs, it is still necessary to develop synthetic routes to new types of these materials is of actual importance. Moreover, the universal methods for modification of the IL structure and preparation of a wide range of new materials by this way are of great interest. Polyfluorinated aryltrifluoroborates are attractive as starting compounds for the synthesis of functional ILs. ${ }^{67-69}$ The cumulative effect of several fluorine atoms in the aromatic ring provides a high chemical stability along with unique electron withdrawing properties characteristic of these compounds. ${ }^{68}$ In the present work we offer a new chemical platform for ionic liquids with specific properties based on polyfluorophenyltrifluoroborate salts. ${ }^{68,69}$

\section{Results and discussion}

\section{Synthesis of ionic liquids}

New ionic liquids were obtained by ion exchange (metathesis) reactions of $\mathrm{Q}^{+} \mathrm{X}^{-}\left(\mathrm{X}=\mathrm{Cl}, \mathrm{Br} ; \mathrm{Q}=\mathrm{Et}_{4} \mathrm{~N}\right.$ (1a), 1-ethyl-3- 
methylimidazolium (EMIM) (1b), 1-butyl-3-methylimidazolium (BMIM) (1c), 1-methyl-3-octylimidazolium (OMIM) (1d) and 1butyl-2,3-dimethylimidazolium (BMMIM) (1e)) with potassium pentafluorophenyltrifluoroborate (2) (Scheme 1). The reactions can be carried out in the solvents where the starting compounds but not the produced potassium halide are readily soluble (for example, acetonitrile or acetone). In acetone, the preferable initial materials are ionic liquids 1 containing chloride ions due to the fact that the alkali metal chlorides, the ion exchange byproduct, are $c a$. 200-300 times less soluble in acetone than the corresponding bromides. In the acetone media the reaction proceeds at room temperature and allows halogen-free ionic liquids 3 to be obtained in the presence of a minor excess of salt 2 to be removed by dissolving the reaction mixture in dichloromethane.

Attempts to prepare $3 \mathbf{a}-\mathbf{e}$ in water led shortly to the formation of a new phase of the hydrophobic ionic liquid. The optimal temperature for this metathesis was found to range from 40 to $60{ }^{\circ} \mathrm{C}$. Higher temperatures favored the phase separation due to a decreased viscosity of ILs, but in parallel way, the solubility of salt 2 in water also increased.

For preparation of 1-butyl-3-methylimidazolium 4-RO2,3,5,6-tetrafluorophenyltrifluoroborates $\mathbf{5 a - h}$ we used the reaction of $\mathrm{BMIMCl}$ with the corresponding salts $\mathbf{4 a - h}$ in acetone (Scheme 2). The salts were obtained by the earlier described reaction of nucleophilic substitution of $p$-fluorine atom in pentafluorotrifluoroborate anion with appropriate nucleophiles. ${ }^{70}$ The same technique was used for synthesis of chiral salts $\mathbf{4 g}$ and $\mathbf{4 h}$ from L(-)-isopulegol and $\mathrm{L}(-)$-borneol respectively.

Alternatively, ionic liquids 5 may be prepared directly from $\mathrm{BMIM}\left[\mathrm{C}_{6} \mathrm{~F}_{5} \mathrm{BF}_{3}\right]$ by nucleophilic substitution with a suitable reagent (Scheme 3 ).

The presented results demonstrate a high synthetic potential of pentafluorophenylborate anion for preparation of new ILs. A variety of ILs can be obtained either by cation metathesis of QX and $\mathrm{K}\left[\mathrm{ArBF}_{3}\right]$ or by modification of $\mathrm{Q}\left[\mathrm{C}_{6} \mathrm{~F}_{5} \mathrm{BF}_{3}\right]$ by an appropriate O-nucleophile. This opens wide opportunities for easy tuning of desired physico-chemical properties of ILs using the optimal synthetic routes.

\section{Thermal properties}

The presented data (Table 1) indicate that the cationic moiety influences significantly the primary characteristics of the

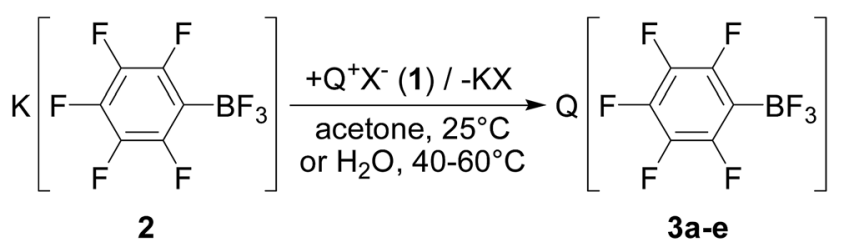
$\mathrm{Q}=\mathrm{Et}_{4} \mathrm{~N}(\mathbf{a}), \operatorname{EMIM}(\mathbf{b}), \operatorname{BMIM}(\mathbf{c}), \operatorname{OMIM}(\mathbf{d}), \operatorname{BMMIM}(\mathbf{e}) ;$
$X=\mathrm{Cl}, \mathrm{Br}$

Scheme 1 Preparation of the ionic liquids based on the $\mathrm{C}_{6} \mathrm{~F}_{5} \mathrm{BF}_{3}$ anion.

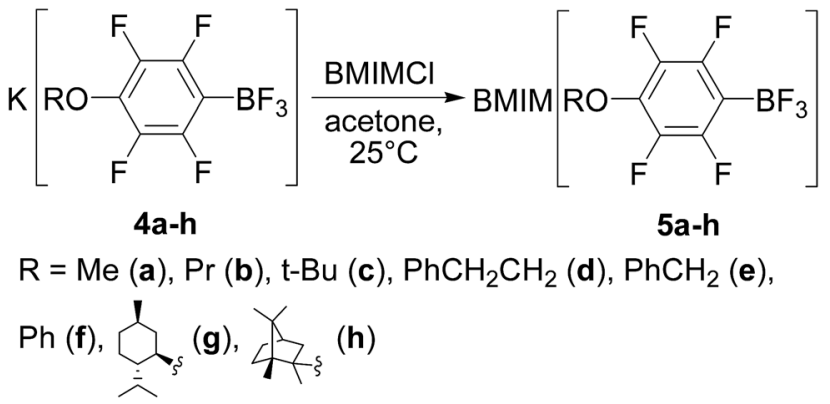

Scheme 2 Preparation of the ionic liquids based on the $\left[4-\mathrm{ROC}_{6} \mathrm{~F}_{4}\right.$ $\mathrm{BF}_{3}$ ]-anions.

resulting material. For example, in contrast to $\mathrm{K}\left[\mathrm{C}_{6} \mathrm{~F}_{5} \mathrm{BF}_{3}\right]$ decomposed at $328-329{ }^{\circ} \mathrm{C},{ }^{71}$ salts 3 are the less thermally stable. ILs $\mathbf{3 b}$-3d are less stable, they are decomposed at ca. $200{ }^{\circ} \mathrm{C}$, whereas the far lower decomposition temperature of $\mathrm{Et}_{4} \mathrm{~N}$ $\left[\mathrm{C}_{6} \mathrm{~F}_{5} \mathrm{BF}_{3}\right]$ 3a is accounted for by the Hofmann-type decomposition of the tetraethylammonium cation. Introduction of a substituent at the para-position of the fluorinated ring does not affect significantly the thermal stability of the compounds: $\mathbf{5 a}-\mathbf{h}$ compounds also are decomposed at $200-220{ }^{\circ} \mathrm{C}$.

The cation nature affects the salt melting temperatures in a more complicated manner. IL $\mathbf{3 a}$ is solid under normal conditions. Salts $\mathbf{3 b}$ and $\mathbf{3} \mathbf{c}$ can be supercooled melts at room temperature. These substances tend to bulk crystallization on cooling but remain at room temperature solid upon heating. Note that a similar effect, i.e. the difference between the melting and freezing points, was described earlier for other ionic liquids based on the dialkylimidazolium cation. ${ }^{46,47,72}$ The IL melting point reduces as the hydrocarbon chain of the imidazolium cation lengthens. We can suppose, by analogy with $\mathrm{Q}^{+} \mathrm{Hal}^{-}$, that the further lengthening of the alkyl constituent (12 carbon atoms and more) of the cation again causes a higher melting point due to a stronger influence of the long hydrocarbon chain on the IL physical properties.

The introduction of a RO group at the para-position of the fluorinated aromatic ring has an evident effect. While $\mathbf{5 f}$ and $\mathbf{5 h}$ are solids (melting points $70-78{ }^{\circ} \mathrm{C}$, see Table 1 ), the other compounds 5 are liquids at room temperature.

Melting points of ionic liquids with substituents of identical nature depend on their structure. In a series of ionic liquids $\mathbf{5 d -}$ f with phenyl and phenylalkyl moieties of the fluorinated anion,

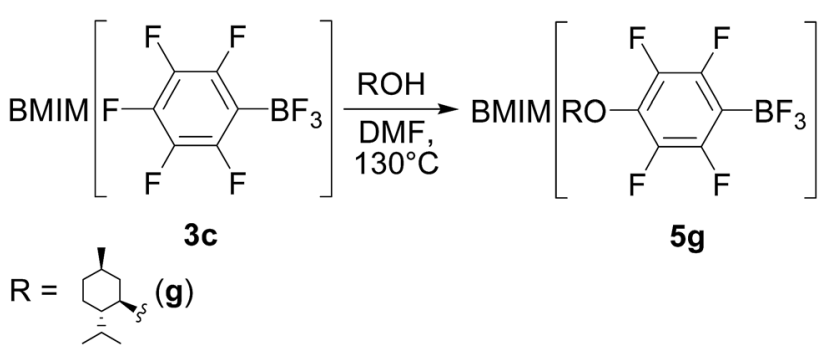

Scheme 3 An alternative approach to preparation of ionic liquids 5 (with preparation $5 \mathrm{~g}$ as an example). 
Table 1 Thermal properties of ionic liquids $\mathrm{Q}\left[\mathrm{ArBF}_{3}\right]$

\begin{tabular}{|c|c|c|}
\hline Ionic liquid & $\begin{array}{l}\text { Melting point, } \\
{ }^{\circ} \mathrm{C}\end{array}$ & $\begin{array}{l}\text { Temperature of } \\
\text { decomposition, }{ }^{a}{ }^{\circ} \mathrm{C}\end{array}$ \\
\hline $\mathrm{BMIM}\left[\mathrm{BF}_{4}\right]$ & $-83^{b}$ & $425^{b}$ \\
\hline $\mathrm{Et}_{4} \mathrm{~N}\left[\mathrm{C}_{6} \mathrm{~F}_{5} \mathrm{BF}_{3}\right](\mathbf{3 a})$ & +55 & 145 \\
\hline $\operatorname{EMIM}\left[\mathrm{C}_{6} \mathrm{~F}_{5} \mathrm{BF}_{3}\right](3 \mathbf{b})$ & +40 & 199 \\
\hline $\mathrm{BMIM}\left[\mathrm{C}_{6} \mathrm{~F}_{5} \mathrm{BF}_{3}\right](3 \mathrm{c})$ & +35 & 203 \\
\hline $\mathrm{OMIM}\left[\mathrm{C}_{6} \mathrm{~F}_{5} \mathrm{BF}_{3}\right](\mathbf{3 d})$ & +10 & 200 \\
\hline $\mathrm{BMMIM}\left[\mathrm{C}_{6} \mathrm{~F}_{5} \mathrm{BF}_{3}\right](3 \mathrm{e})$ & +35 & 219 \\
\hline $\mathrm{BMIM}\left[4-\mathrm{MeOC}_{6} \mathrm{~F}_{4} \mathrm{BF}_{3}\right](5 \mathrm{a})$ & +9 & 217 \\
\hline $\operatorname{BMIM}\left[4-\mathrm{PrOC}_{6} \mathrm{~F}_{4} \mathrm{BF}_{3}\right](5 \mathbf{b})$ & -3 & 223 \\
\hline $\mathrm{BMIM}\left[4-t-\mathrm{BuOC}_{6} \mathrm{~F}_{4} \mathrm{BF}_{3}\right](5 \mathrm{c})$ & +33 & 227 \\
\hline $\begin{array}{l}\mathrm{BMIM}\left[4-\mathrm{Ph}\left(\mathrm{CH}_{2}\right)_{2} \mathrm{OC}_{6} \mathrm{~F}_{4} \mathrm{BF}_{3}\right] \\
(\mathbf{5 d})\end{array}$ & $\sim-50^{c}$ & 218 \\
\hline $\mathrm{BMIM}\left[4-\mathrm{PhCH}_{2} \mathrm{OC}_{6} \mathrm{~F}_{4} \mathrm{BF}_{3}\right](5 \mathrm{e})$ & +22 & 210 \\
\hline $\mathrm{BMIM}\left[4-\mathrm{PhOC}_{6} \mathrm{~F}_{4} \mathrm{BF}_{3}\right](\mathbf{5 f})$ & +78 & 219 \\
\hline $\begin{array}{l}\mathrm{BMIM}\left[4 \text {-isopulegylOC } 6 \mathrm{~F}_{4} \mathrm{BF}_{3}\right] \\
(\mathbf{5 g})\end{array}$ & $\sim-50^{c}$ & 208 \\
\hline $\mathrm{BMIM}\left[4\right.$-bornylOC $\left.{ }_{6} \mathrm{~F}_{4} \mathrm{BF}_{3}\right](5 \mathbf{h})$ & +70 & 205 \\
\hline
\end{tabular}

the melting temperature decreases with increasing of the substituents in size. This is not the same with ionic liquids containing aliphatic structural fragments of the anion. Ionic liquids $\mathbf{5 c}$ and $\mathbf{5 h}$ contain bulky fragments of the anions but melt at a relatively high temperature, while $\mathbf{5 a}$ with a small $\mathrm{MeO}$ substituent at a slightly lower temperature. We failed to observe crystallization of ionic liquid $\mathbf{5 g}$ containing an isopulegol fragment.

In common, the reduced meting point of IL is though to result from asymmetry of at least one of the ions. However, there is no clarity in the case. Melting points of $\operatorname{EMIM}\left[\mathrm{C}_{n^{-}}\right.$ $\left.\mathrm{H}_{2 n+1} \mathrm{BF}_{3}\right](n=1-5)$ vary from $-14(n=3)$ to $-9(n=4)$ and $16{ }^{\circ} \mathrm{C}$ $(n=5)$ while EMIM $\left[\mathrm{BF}_{4}\right]$ melts at $15{ }^{\circ} \mathrm{C}^{73}$ This is also the case with their analogues, $\operatorname{EMIM}\left[\mathrm{C}_{n} \mathrm{~F}_{2 n+1} \mathrm{BF}_{3}\right]$, that melt at $-1,8$ and $-20{ }^{\circ} \mathrm{C}$ at $n=2,3$ and 4 , respectively. ${ }^{54}$ In our series, melting points are much higher than those of $\mathrm{BMIM}\left[\mathrm{BF}_{4}\right]$ (Table 1). It may happen that the presence of boron atom gives rise to additional interactions and, therefore, to more compact relative position of anions and cations. An indirect evidence of this assumption may be the density of salt $3 \mathbf{c}\left(1.68 \mathrm{~g} \mathrm{~mL}^{-1}\right)$ which close to that of $\operatorname{BMIM}\left[\mathrm{BF}_{4}\right]\left(1.21 \mathrm{~g} \mathrm{~mL}^{-1}\right)$. The further reduction of the anion symmetry due to introduction of a substituent at the para-position to boron of the polyfluoroaromatic ring leads in most cases to a decrease in the melting temperature of ILs. If so, behavior of the salts seems abnormal. In the case of salts $\mathbf{5 d -}$ f the melting temperature increases, apparently, due to the $\pi$ stacking interaction between the phenyl group and the substituted tetrafluorophenyl group. Such an interaction is weakened substantially in the salts by respective bridging groups that prevent the local microstructuring in ILs.

\section{Spectral properties}

Chemical compositions of ILs were studied by ${ }^{1} \mathrm{H},{ }^{11} \mathrm{~B},{ }^{13} \mathrm{C}$ and ${ }^{19} \mathrm{~F}$ NMR spectroscopy as well as by elemental analysis. While chemical shifts in the spectra of imidazolium salts depend strongly on the solvent and concentration, ${ }^{74-78}$ the NMR spectra of $3 \mathbf{a}-\mathbf{e}$ and $\mathbf{5 a}-\mathbf{h}$ were acquired with the solutions in $\mathrm{CDCl}_{3}$ at the concentration of $c a .30 \mathrm{~g} \mathrm{~L}^{-1}$. The obtained NMR data are presented in Table 2.

In the ${ }^{1} \mathrm{H}$ NMR spectrum, the chemical shift of the ring hydrogen $\mathrm{H}-2$ in 1,3-dialkylimidazolium cation correlates with the cation-anion hydrogen bonding strength and with the inductive effect of proximity of anion to cation. ${ }^{74-79}$ For example, in the series of BMIM $\mathrm{X}$ the chemical shift $\delta(\mathrm{H}-2)$ moves from $10.22(\mathrm{X}=\mathrm{Cl})$, to $9.78(\mathrm{X}=\mathrm{Br}), 9.28(\mathrm{X}=\mathrm{I})$ and $8.50(\mathrm{X}=$ $\left.\mathrm{BF}_{4}\right)$ ppm. ${ }^{79}$ The chemical shift of $\mathrm{H}-2$ in the spectra of EMIM $\left[\mathrm{C}_{6} \mathrm{~F}_{5} \mathrm{BF}_{3}\right], \mathrm{BMIM}\left[\mathrm{C}_{6} \mathrm{~F}_{5} \mathrm{BF}_{3}\right]$, and $\mathrm{OMIM}\left[\mathrm{C}_{6} \mathrm{~F}_{5} \mathrm{BF}_{3}\right]$ show the less, but remarkable change of location that correlates with increase of length of alkyl chain. However, the effect of anion $\left[\mathrm{C}_{6} \mathrm{~F}_{5} \mathrm{BF}_{3}\right]$ is weaker than effect of $\left[\mathrm{BF}_{4}\right]$. In the ${ }^{13} \mathrm{C}$ NMR spectrum, signals of $\mathrm{C}-2$ behave similar way: the carbon atom is more deshielded in $\mathrm{BMIM}\left[\mathrm{BF}_{4}\right]$ than in $\mathrm{BMIM}\left[\mathrm{C}_{6} \mathrm{~F}_{5} \mathrm{BF}_{3}\right]$. Elongation of the carbon chain at $\mathrm{C}-3$ leads to shielding of carbon $\mathrm{C}-2$, although the range of difference is only $0.07 \mathrm{ppm}\left(c f . \Delta \delta(\mathrm{C})=\delta(\mathrm{C}-2)\left(\mathrm{OMIM}^{2} \mathrm{BF}_{4}\right]\right)-$ $\left.\delta(\mathrm{C}-2)\left(\mathrm{OMIM}\left[\mathrm{NTf}_{2}\right]\right)=0.8 \mathrm{ppm}^{74-78}\right)$.

The contribution of hydrogen bond (C-2)-H $\cdots \mathrm{F}-\mathrm{B}$ in NMR spectra of $\mathbf{3 b}-\mathbf{d}$ is seen clearly when comparing ${ }^{11} \mathrm{~B}$ and ${ }^{19} \mathrm{~F}$ NMR spectra of $\mathrm{Et}_{4} \mathrm{~N}\left[\mathrm{C}_{6} \mathrm{~F}_{5} \mathrm{BF}_{3}\right]$ and $\mathrm{BMMIM}\left[\mathrm{C}_{6} \mathrm{~F}_{5} \mathrm{BF}_{3}\right]$ where this intermolecular interaction is absent and chemical shifts of both boron and fluorine atoms of $\mathrm{BF}_{3}$ moiety are determined mainly by the Coulomb forces. Indeed, signals of fluorine atoms bonded to boron in anion $\left[\mathrm{C}_{6} \mathrm{~F}_{5} \mathrm{BF}_{3}\right]$ are located at $-136 \mathrm{ppm}$ while the corresponding atoms in spectra of $\mathbf{3 b} \mathbf{b}-\mathbf{3 d}$ are remarkably deshielded. The boron atoms in counteranions of 3b-d are deshielded too with respect to positions of the ${ }^{11} \mathrm{~B}$ resonances in spectra of $3 \mathbf{a}$ and $3 \mathbf{e}$ which located at 1.76 and $1.86 \mathrm{ppm}$ (Table 2).

In common, replacement of fluorine atom at the position para to boron by RO substituent increases the cation-anion aggregation. The ${ }^{1} \mathrm{H}$ and ${ }^{13} \mathrm{C}$ NMR spectra of BMIM cation

Table 2 Selected NMR data for ILs Q $\left[\mathrm{RBF}_{3}\right]$

\begin{tabular}{|c|c|c|c|c|}
\hline \multirow[b]{2}{*}{ Ionic liquid $\mathrm{Q}\left[\mathrm{RBF}_{3}\right]$} & \multicolumn{4}{|c|}{ Chemical shift, ppm } \\
\hline & ${ }^{1} \mathrm{H}^{a}$ & ${ }^{13} \mathrm{C}^{b}$ & ${ }^{11} \mathrm{~B}$ & ${ }^{19} \mathrm{~F}^{c}$ \\
\hline $\mathrm{BMIM}\left[\mathrm{BF}_{4}\right]$ & 8.83 & 136.91 & -0.99 & -152.67 \\
\hline $\mathrm{BMMIM}\left[\mathrm{BF}_{4}\right]$ & - & 143.95 & -1.24 & -153.83 \\
\hline $\mathrm{Et}_{4} \mathrm{~N}\left[\mathrm{C}_{6} \mathrm{~F}_{5} \mathrm{BF}_{3}\right](\mathbf{3 a})$ & - & - & 1.86 & -135.93 \\
\hline $\operatorname{EMIM}\left[\mathrm{C}_{6} \mathrm{~F}_{5} \mathrm{BF}_{3}\right](3 \mathbf{b})$ & 9.00 & 136.64 & 2.05 & -135.00 \\
\hline $\operatorname{BMIM}\left[\mathrm{C}_{6} \mathrm{~F}_{5} \mathrm{BF}_{3}\right](3 \mathrm{c})$ & 8.89 & 136.60 & 2.03 & -134.83 \\
\hline $\mathrm{OMIM}\left[\mathrm{C}_{6} \mathrm{~F}_{5} \mathrm{BF}_{3}\right](\mathbf{3 d})$ & 8.90 & 136.57 & 2.03 & -134.79 \\
\hline $\mathrm{BMMIM}\left[\mathrm{C}_{6} \mathrm{~F}_{5} \mathrm{BF}_{3}\right](3 \mathbf{e})$ & - & - & 1.76 & -136.14 \\
\hline $\operatorname{BMIM}\left[4-\mathrm{MeOC}_{6} \mathrm{~F}_{4} \mathrm{BF}_{3}\right](\mathbf{5 a})$ & 8.99 & 136.71 & 2.14 & -134.60 \\
\hline $\mathrm{BMIM}\left[4-\mathrm{PrOC}_{6} \mathrm{~F}_{4} \mathrm{BF}_{3}\right](5 \mathbf{b})$ & 8.79 & 136.37 & 2.17 & -134.60 \\
\hline $\operatorname{BMIM}\left[4-t-\mathrm{BuOC}_{6} \mathrm{~F}_{4} \mathrm{BF}_{3}\right](5 \mathrm{c})$ & 8.68 & 136.19 & 2.19 & -134.40 \\
\hline $\operatorname{BMIM}\left[4-\mathrm{Ph}\left(\mathrm{CH}_{2}\right)_{2} \mathrm{OC}_{6} \mathrm{~F}_{4} \mathrm{BF}_{3}\right](5 d)$ & 8.90 & 136.69 & 2.20 & -134.63 \\
\hline $\mathrm{BMIM}\left[4-\mathrm{PhCH}_{2} \mathrm{OC}_{6} \mathrm{~F}_{4} \mathrm{BF}_{3}\right](5 \mathrm{e})$ & 9.00 & 136.24 & 2.18 & -134.80 \\
\hline $\mathrm{BMIM}\left[4-\mathrm{PhOC}_{6} \mathrm{~F}_{4} \mathrm{BF}_{3}\right](\mathbf{5 f})$ & 8.77 & 136.25 & 2.16 & -134.50 \\
\hline $\operatorname{BMIM}\left[4\right.$-isopulegylOC $\left.{ }_{6} \mathrm{~F}_{4} \mathrm{BF}_{3}\right](5 \mathrm{~g})$ & 8.93 & 136.65 & 2.19 & -134.53 \\
\hline $\mathrm{BMIM}\left[4\right.$-bornylOC $\left.{ }_{6} \mathrm{~F}_{4} \mathrm{BF}_{3}\right](5 \mathrm{~h})$ & 8.93 & 136.79 & 2.15 & -134.54 \\
\hline
\end{tabular}


Table 3 Solubility of ILs in water and organic solvents

\begin{tabular}{|c|c|c|c|c|c|c|c|c|}
\hline \multicolumn{9}{|c|}{ Solubility of ILs in solvents ${ }^{a}$} \\
\hline $\mathrm{Et}_{4} \mathrm{~N}\left[\mathrm{C}_{6} \mathrm{~F}_{5} \mathrm{BF}_{3}\right](3 \mathrm{a})$ & - & - & + & + & - & + & + & + \\
\hline $\operatorname{EMIM}\left[\mathrm{C}_{6} \mathrm{~F}_{5} \mathrm{BF}_{3}\right](3 \mathbf{b})$ & - & - & + & + & - & + & + & + \\
\hline $\mathrm{BMIM}\left[\mathrm{C}_{6} \mathrm{~F}_{5} \mathrm{BF}_{3}\right](3 \mathrm{c})$ & - & - & + & + & - & + & + & + \\
\hline $\mathrm{BMIM}\left[4-\mathrm{MeOC}_{6} \mathrm{~F}_{4} \mathrm{BF}_{3}\right](\mathbf{5 a})$ & \pm & - & + & + & + & + & + & + \\
\hline $\mathrm{BMIM}\left[4-\mathrm{PrOC}_{6} \mathrm{~F}_{4} \mathrm{BF}_{3}\right](5 \mathbf{b})$ & \pm & - & + & + & + & + & + & + \\
\hline $\operatorname{BMIM}\left[4-t-\mathrm{BuOC}_{6} \mathrm{~F}_{4} \mathrm{BF}_{3}\right](\mathbf{5 c})$ & - & - & - & + & + & + & + & + \\
\hline $\mathrm{BMIM}\left[4-\mathrm{Ph}\left(\mathrm{CH}_{2}\right)_{2} \mathrm{OC}_{6} \mathrm{~F}_{4} \mathrm{BF}_{3}\right](5 \mathrm{~d})$ & - & - & + & + & - & + & + & + \\
\hline $\mathrm{BMIM}\left[4-\mathrm{PhCH}_{2} \mathrm{OC}_{6} \mathrm{~F}_{4} \mathrm{BF}_{3}\right](5 \mathrm{e})$ & - & - & + & + & - & + & + & + \\
\hline $\operatorname{BMIM}\left[4-\mathrm{PhOC}_{6} \mathrm{~F}_{4} \mathrm{BF}_{3}\right](\mathbf{5 f})$ & - & - & + & + & - & + & + & + \\
\hline
\end{tabular}

${ }^{a}(+)$ soluble $\left(>10 \mathrm{mg} \mathrm{mL}^{-1}\right),(-)$ insoluble $\left(<1 \mathrm{mg} \mathrm{mL}^{-1}\right),( \pm)$ poorly soluble. ${ }^{b}$ Methanol, ethanol, acetone and acetonitrile. ${ }^{c}$ Chlorocarbons: dichloromethane, trichloromethane, 1,2-dichloroethane. ${ }^{d} \mathrm{BMIM}\left[\mathrm{BF}_{4}\right]$ is insoluble in isopropanol.

indicate stronger hydrogen bonding with anion in $\mathbf{5 a}, \mathbf{5 b}, \mathbf{5 d}-\mathbf{h}$ than in $\mathrm{BMIM}\left[\mathrm{C}_{6} \mathrm{~F}_{5} \mathrm{BF}_{3}\right]$. This also confirms by the deshielding of ${ }^{11} \mathrm{~B}$ and ${ }^{19} \mathrm{~F}$ resonances of $\mathrm{BF}_{3}$ moiety of $\left[4-\mathrm{ROC}_{6} \mathrm{~F}_{4} \mathrm{BF}_{3}\right]$ relative those in $\left[\mathrm{C}_{6} \mathrm{~F}_{5} \mathrm{BF}_{3}\right]$. The peculiar case is $\mathrm{BMIM}\left[4-t-\mathrm{BuOC}_{6}-\right.$ $\left.\mathrm{F}_{4} \mathrm{BF}_{3}\right]$ 5c. Both hydrogen and carbon atoms of the $(\mathrm{C}-2)-\mathrm{H}$ moiety are more shielded than those in BMIM $\left[\mathrm{BF}_{4}\right]$ and BMIM $\left[\mathrm{C}_{6} \mathrm{~F}_{5} \mathrm{BF}_{3}\right]$. These parameters meet the criteria of the weak cation-anion interaction, e.g. their state as solvent-separated ion pair. On the other hand, the ${ }^{11} \mathrm{~B}$ and ${ }^{19} \mathrm{~F}$ NMR spectra show deshielding of boron and fluorines atoms similar to that in salts 5 (contact ion pair). We prefer to consider the spectral performance data on counteranion as a more reliable indicator of salt aggregation in the solution and believe that the observed features reflect the different organisation of contact ion pair $\mathbf{5 c}$ in $\mathrm{CDCl}_{3}$ with respect to contact ion pair $\mathbf{5 a}, \mathbf{5 b}, \mathbf{5 d}-\mathbf{h}$ because of bulky tert-butyl moiety at para-position to boron.

\section{Miscibility of ILs with water and organic solvents}

Data on the solubility of prepared ILs in water and organic solvents are presented in Table 3. They all except BMIM[ $\left[\mathrm{BF}_{4}\right]$ are seen to be insoluble or poorly soluble in water. Nevertheless, even though ionic liquids $\mathbf{5 a}$ and $\mathbf{5 b}$ exhibit hydrophobic properties, their solubility in water is rather different from the solubility of the other ionic liquids.

The solubility of ionic liquids in water is one of the most studied subjects; it differs significantly from the dissolution process of conventional salts. The interaction of cations and anions with water molecules should be considered separately when interpreting experimental data on the water solubility of ILs. Since the imidazolium and related cations possess amphiphilic properties, ${ }^{80}$ the corresponding ILs can behave as surfactants and self-assemble into various aggregates in aqueous media.$^{81}$ In general, the process of water dissolution is mainly determined by solvation of anions. The energy of such interaction in the case of anions can be as high as two times of the similar energy for cations. ${ }^{82}$ This fact explains adequately the lack of observable effects during the interaction of salts $\mathbf{3 b}-$ d with water.

Substitution of the hydrophobic pentafluorophenyl group for a fluorine atom in $\mathrm{BF}_{4}{ }^{-}$leads to a decrease in the anion solvation energy. As a result, salts $\mathbf{3 a - e}$ and $\mathbf{5 c}-\mathbf{h}$ are water insoluble. A better solubility of ionic liquids $\mathbf{5 a}$ and $\mathbf{5 b}$ can be caused by the participation of oxygen atoms of the alkoxide moiety in the formation of hydrogen bonds with water molecules. In fact, ILs $\mathbf{5 a}$ and $\mathbf{5 b}$ can be both hydrogen bond acceptor (anion) and donor (cation) and are expected to interact with solvents bearing both accepting and donating sites. ${ }^{83}$ Ionic liquids $\mathbf{5} \mathbf{c}-\mathbf{h}$ with oxygen containing anions are poorly soluble in water, probably, due to segregation of the oxygen atoms that prevents the formation of hydrogen bonds.

In contrast to $\mathrm{Q}\left[\mathrm{BF}_{4}\right]$, ILs $\mathbf{3 a} \mathbf{a}-\mathbf{e}$ and $\mathbf{5 a} \mathbf{a}-\mathbf{h}$ are freely soluble in benzene. Introduction of polyfluorinated aromatic moiety into the anion is expected to improve the solubility of ILs in aromatics (due to additional intramolecular interactions such as $\pi$-stacking) but not in saturated hydrocarbons. In $\mathbf{5 c}$, the tertbutyl group prevents interaction of the $\pi$-system in anion with the aromatic component of the solvent and, therefore, makes the salt poorly soluble.

Similar to aqueous ILs solutions, the mixtures of the prepared ILs with benzene are more complex than conventional mixtures of ILs with neutral solvents. The microstructure of such mixtures is largely determined by the interaction of cations with the solvent molecules, ${ }^{84-86}$ but systematic studies of the dependence of the microscopic structure of "ionic liquid aromatic solvent" systems on the anion nature are as yet unknown. One of the first works in the area has been published recently. ${ }^{78}$

There is a more ambiguous case when an aromatic compound and ionic liquids are the solute and solvent, respectively. From literature, ${ }^{87,88}$ the benzene solubility is $1.2-$ 2 mol per mol of BMIM[BF $\left.\mathrm{BF}_{4}\right]$. The substitution of $\left[\mathrm{C}_{6} \mathrm{~F}_{5} \mathrm{BF}_{3}\right]$ for 
$\left[\mathrm{BF}_{4}\right]$ increases the benzene solubility up to seven mol per mol $\mathrm{BMIM}\left[\mathrm{C}_{6} \mathrm{~F}_{5} \mathrm{BF}_{3}\right]$ that agrees with the assumed role of $\pi$-stacking between the aromatic solute and IL solvents.

The influence of the cation nature is illustrated with IL $\mathbf{3 b}-$ d as an example. Elongation of the alkyl chain in IL leads to stronger hydrophobic properties and to a good solubility of IL 3d in diethyl ether. Other ILs with the pentafluorophenyltrifluoroborate anions are insoluble in this solvent. Introduction of an alkoxide moiety into the polyfluoroaromatic ring of the anion makes the corresponding ionic liquids soluble in $\mathrm{Et}_{2} \mathrm{O}$ of. However, this is not the case of salts $\mathbf{5 d - f}$.

ILs $\mathbf{3 a}-\mathbf{e}$ and $\mathbf{5 a}-\mathbf{h}$ are insoluble in hydrocarbons but soluble in polar organic solvents (acetone, acetonitrile, alcohols, chloroalkanes). In contrast to the BMIM $\left[\mathrm{BF}_{4}\right]$, ILs 3a-e and $\mathbf{5 a - h}$ are soluble in ethyl acetate.

Thus, the above data demonstrate clearly that the substitution of a pentafluorophenyl group for fluorine in $\mathrm{BF}_{4}$ anion can change significantly the solubility of the corresponding ionic liquids in water and organic solvents. The introduction of an alkoxy or aryloxy substituent in the perfluorinated aromatic ring allows some properties of the resulting ILs to be changed. This feature opens up opportunities for applying ILs in various fields.

\section{Other properties of ILs}

The optical rotation of chiral ionic liquids was measured. The $\alpha_{\mathrm{D}}^{20}$ for chiral ILs $5 \mathrm{~g}$ and $\mathbf{5 h}$ (acetone, $1.00 \mathrm{~g} / 100 \mathrm{~mL}$ ) are -10.7 and $-\mathbf{1 5 . 2}$ respectively. This is less as 2.4 times of the optical rotation of isopulegol $\left(\alpha_{\mathrm{D}}^{20}=-25.9\right)$ and borneol $\left(\alpha_{\mathrm{D}}^{20}=-37.9\right)$. Since, according to NMR, we do not observed significantly structural and electronic changes in chiral substituent in the IL structure, the decrease in $\alpha_{\mathrm{D}}^{20}$ can be accounted for by a decrease in the relative content of chiral centers per unit mass. The viscosity of IL's 3 was measured. We observed that prepared ionic liquids are more viscous than $\mathrm{BMIM}\left[\mathrm{BF}_{4}\right]$ and viscosity increases with the cation size (the data of viscosity measurements are available in the ESI†).

\section{Experimental}

The NMR spectra were recorded on a Bruker AVANCE III $500\left({ }^{1} \mathrm{H}\right.$ at $500.13 \mathrm{MHz},{ }^{11} \mathrm{~B}$ at $160.46 \mathrm{MHz},{ }^{13} \mathrm{C}$ at $125.76 \mathrm{MHz}$, and ${ }^{19} \mathrm{~F}$ at $470.59 \mathrm{MHz}$ ) spectrometer. The chemical shifts were referenced to TMS $\left({ }^{1} \mathrm{H},{ }^{13} \mathrm{C}\right), \mathrm{BF}_{3} \mathrm{O}\left(\mathrm{C}_{2} \mathrm{H}_{5}\right)_{2}$ in $\mathrm{CDCl}_{3}(15 \% \mathrm{v} / \mathrm{v})\left({ }^{11} \mathrm{~B}\right)$, and $\mathrm{CCl}_{3} \mathrm{~F}\left({ }^{19} \mathrm{~F}\right.$, with $\mathrm{C}_{6} \mathrm{~F}_{6}$ as secondary reference $\left.(-162.9 \mathrm{ppm})\right)$.

TG-DSC analyses were performed using a Netzsch STA409 instrument with a heating rate of $10 \mathrm{~K} \mathrm{~min}^{-1}$ under He flow. The melting points (for ILs 3 ) were determined from DSC curves as $T_{\text {onset }}$. Temperature of decomposition $\left(T_{\mathrm{d}}\right)$ was determined from the TG diagrams as $T_{\text {onset }}$.

Optical rotations were measured on a polAAr 3005 polarimeter with a $100 \mathrm{~mm}$ cell.

The melting points of the ionic liquids $\mathbf{5}$ were estimated visually by keeping of IL sample upon continuously increasing temperature (with the rate $\sim 1{ }^{\circ} \mathrm{C} \mathrm{min}^{-1}$ ) using the LOIP FT 311 80 cryostat $\left(-80\right.$ to $\left.+100{ }^{\circ} \mathrm{C}\right)$.
Elemental analysis was performed in the Collective Service Center of SB RAS (Novosibirsk).

DMF was purified by distillation over $\mathrm{P}_{4} \mathrm{O}_{10}$ under reduced pressure. $\mathrm{NaH}$ (60\% dispersion in mineral oil) (Sigma-Aldrich), $\mathrm{L}(-)$-borneol (Acros) and other commercially available was used as supplied. Potassium pentafluorophenyltrifluoroborate (2) was prepared according to literature method. ${ }^{89}$ Potassium 4-ROtetrafluorophenyltrifluoroborates $(\mathbf{4 a - f})$ were prepared according to described methods. ${ }^{70}$

\section{Potassium (1R,2S,5R)-5-methyl-2-(prop-1-en-2-yl) cyclohexyloxy-2,3,5,6-tetrafluorophenyltrifluoroborate (4g)}

A $100 \mathrm{~mL}$ round-bottomed flask fitted with magnetic stirrer bar and an argon supply equipment was charged with $5.43 \mathrm{~g}$ (35 $\mathrm{mmol}$ ) of $\mathrm{L}(-)$-isopulegol. $1.28 \mathrm{~g}$ (32 $\mathrm{mmol})$ of $60 \%$ dispersion $\mathrm{NaH}$ was added in portions and then $40 \mathrm{~mL}$ DMF was added. The resulted mixture was stirred at $25{ }^{\circ} \mathrm{C}$ for $1 \mathrm{~h}$ under an atmosphere of argon, and then $\mathrm{K}\left[\mathrm{C}_{6} \mathrm{~F}_{5} \mathrm{BF}_{3}\right](6.03 \mathrm{~g}, 22 \mathrm{mmol})$ was added in one portion. The flask was put into heating bath at $130{ }^{\circ} \mathrm{C}$ and the reaction mixture was stirred for $5 \mathrm{~h}$ at this temperature. Then it was cooled and $5 \mathrm{~mL}$ of water was added. The resulting mixture was transferred into $250 \mathrm{~mL}$ PP cup. $17.18 \mathrm{~g}(220 \mathrm{mmol})$ of $\mathrm{KHF}_{2}$ was added and mixture was stirred for $8 \mathrm{~h}$ at room temperature. To a resulting suspension $1.1 \mathrm{~g}$ (8 mmol) $\mathrm{K}_{2} \mathrm{CO}_{3}$ and $40 \mathrm{~mL}$ of acetonitrile were added and suspension was stirred for $1 \mathrm{~h}$. The suspension was filtered through the silica gel $(60-200 \mu \mathrm{m}, \sim 40 \mathrm{~mL})$ and cake was washed by $2 \times 20 \mathrm{~mL}$ of acetonitrile, filtrate was evaporated in vacuo. The product was purified by recrystallization from 120 $\mathrm{mL}$ of ethanol and dried in vacuum-desiccator. $5.60 \mathrm{~g}(63 \%)$ of $\mathbf{4 g}$ as white powder was prepared.

${ }^{1} \mathrm{H}$ NMR (acetone- $\left.\mathrm{d}_{6}\right)$ : $\delta$ 4.80-4.85 $\left(\mathrm{m}, 1 \mathrm{H}, H_{a}-\mathrm{CH}=\right) ; 4.72-$ $4.77\left(\mathrm{~m}, 1 \mathrm{H}, H_{b}-\mathrm{CH}=\right) ; 4.21\left(\mathrm{td}, 1 \mathrm{H},{ }^{3} J_{\mathrm{HH}} 10.5 \mathrm{~Hz},{ }^{3} J_{\mathrm{HH}} 4.4 \mathrm{~Hz}\right.$, $H$-1); 2.22-2.30 (m, 1H, H-5); $1.96\left(\mathrm{dt}, 1 \mathrm{H},{ }^{3} J_{\mathrm{HH}} 12.2 \mathrm{~Hz},{ }^{3} J_{\mathrm{HH}}\right.$ $3.9 \mathrm{~Hz}, \mathrm{H}-2$ ); 1.77 (dd, 3H, ${ }^{4} \mathrm{~J}_{\mathrm{HH}} 1.5 \mathrm{~Hz},{ }^{4} J_{\mathrm{HH}} 0.8 \mathrm{~Hz}, \mathrm{CH}_{3}-\mathrm{C}=$ ); 1.64-1.71 (m, 2H, $\left.\mathrm{CH}_{2}-6\right)$; 1.42-1.53 (m, 2H, H-3,4); 0.96-1.18 (m, 2H, H-3,4); 0.91 (d, 3H, ${ }^{3} J_{\mathrm{HH}} 6.7 \mathrm{~Hz}, \mathrm{CH}_{3}-5$ ).

${ }^{19} \mathrm{~F}$ NMR (acetone- $\mathrm{d}_{6}$ ): $\delta-133.46\left(\mathrm{q}, 3 \mathrm{~F},{ }^{2} J_{\mathrm{BF}} 42.8 \mathrm{~Hz}, \mathrm{~B} F_{3}\right.$ ), -135.53 (ddq, 2F, ${ }^{3} J_{\mathrm{FF}} 23.0 \mathrm{~Hz},{ }^{5} J_{\mathrm{FF}} 11.8 \mathrm{~Hz},{ }^{4} J_{\mathrm{FF}(\mathrm{BF} 3)} 11.7 \mathrm{~Hz}, F^{-}$ 2,6); -157.99 (dd, 2F, $\left.{ }^{3} J_{\mathrm{FF}} 23.9 \mathrm{~Hz},{ }^{5} J_{\mathrm{FF}} 11.0 \mathrm{~Hz}, F-3,5\right)$.

\section{Potassium 4-bornyloxy-2,3,5,6-} tetrafluorophenyltrifluoroborate $(4 \mathrm{~h})$

A $250 \mathrm{~mL}$ round-bottomed flask fitted with magnetic stirrer bar and an argon supply equipment was charged with $10.86 \mathrm{~g}$ (70 mmol) $\mathrm{L}(-)$-borneol. $85 \mathrm{~mL}$ of DMF and $2.46 \mathrm{~g}$ (64 mmol) of $60 \%$ dispersion $\mathrm{NaH}$ were added. The resulted mixture was stirred at $25{ }^{\circ} \mathrm{C}$ for $1 \mathrm{~h}$ under an atmosphere of argon, and $\mathrm{K}\left[\mathrm{C}_{6} \mathrm{~F}_{5} \mathrm{BF}_{3}\right]$ $(12.06 \mathrm{~g}, 44 \mathrm{mmol})$ was added in one portion. The flask was put into heating bath at $130{ }^{\circ} \mathrm{C}$ and the reaction mixture was stirred for $5 \mathrm{~h}$. The reaction mixture was cooled and $10 \mathrm{~mL}$ of water was added. The resulting mixture was transferred into $500 \mathrm{~mL} P P$ cup. $34.37 \mathrm{~g}$ ( $440 \mathrm{mmol})$ of $\mathrm{KHF}_{2}$ was added and mixture was stirred for $8 \mathrm{~h}$ at room temperature. $\mathrm{K}_{2} \mathrm{CO}_{3}(2.2 \mathrm{~g}, 16 \mathrm{mmol})$ and $80 \mathrm{~mL}$ of acetonitrile were added and then suspension was stirred for $1 \mathrm{~h}$. The suspension was filtered trough the silica gel 
(60-200 $\mu \mathrm{m}, \sim 80 \mathrm{~mL})$ and cake was washed by $2 \times 40 \mathrm{~mL}$ of acetonitrile, the collected filtrate was evaporated in vacuo. The product was purified by recrystallization from $150 \mathrm{~mL}$ of ethanol and dried in vacuum-desiccator. $10.00 \mathrm{~g}(55 \%)$ of product $4 \mathrm{~h}$ as white powder was prepared.

${ }^{1} \mathrm{H}$ NMR (acetone- $\left.\mathrm{d}_{6}\right): \delta 4.45\left(\mathrm{~d}, 1 \mathrm{H} ;{ }^{3} \mathrm{~J}_{\mathrm{HH}} 10 \mathrm{~Hz}, H-2\right) ; 2.19-$ 2.31 (m, 2H, H-3,6); 1.76-1.80 (m, 1H, H-5); 1.69 (dd, $1 \mathrm{H},{ }^{3} J_{\mathrm{HH}}$ $\left.4.5 \mathrm{~Hz} ;{ }^{3} J_{\mathrm{HH}} 4.5 \mathrm{~Hz}, H-4\right)$; 1.28-1.39 (m, 3H, H-3,5,6); 0.95 (s, 3H, $\left.\mathrm{CH}_{3}-\mathrm{C} 7\right) ; 0.90$ (s, 3H, $\left.\mathrm{CH}_{3}-\mathrm{C} 7\right) ; 0.88$ (s, 3H, $\left.\mathrm{CH}_{3}-\mathrm{C} 1\right)$.

${ }^{19} \mathrm{~F}$ NMR (acetone- $\mathrm{d}_{6}$ ): $\delta-133.26\left(\mathrm{q}, 3 \mathrm{~F},{ }^{2} J_{\mathrm{BF}} 43.5 \mathrm{~Hz}, \mathrm{~B} F_{3}\right.$ ), -136.57 (ddq, 2F, ${ }^{3} J_{\mathrm{FF}} 23.2 \mathrm{~Hz} ;{ }^{5} J_{\mathrm{FF}} 11.6 \mathrm{~Hz} ;{ }^{4} J_{\mathrm{FF}\left(\mathrm{BF}_{3}\right)} 11.5 \mathrm{~Hz}, F-$ 2,6); -158.41 (dd, 2F, $\left.{ }^{3} J_{\mathrm{FF}} 23.9 \mathrm{~Hz},{ }^{5} J_{\mathrm{FF}} 10.9 \mathrm{~Hz}, F-3,5\right)$.

\section{General procedure for preparation of $\mathrm{Q}\left[\mathrm{ArBF}_{3}\right]$}

Preparation of ILs in water. A $100 \mathrm{~mL}$ beaker was charged with $5.5 \mathrm{mmol}$ of corresponding tetraalkylammonium or 1,3dialkylimidazolium halide, $5 \mathrm{mmol}$ of $\mathrm{K}\left[\mathrm{C}_{6} \mathrm{~F}_{5} \mathrm{BF}_{3}\right]$ and $40 \mathrm{~mL}$ of water. The mixture was stirred at $50^{\circ} \mathrm{C}$ for $2 \mathrm{~h}$. The water phase was removed by decantation and IL phase was washed by $2 \times 20$ $\mathrm{mL}$ of warm $\left(50{ }^{\circ} \mathrm{C}\right)$ water. The products were dried in high vacuo.

Preparation of ILs in acetone. A $50 \mathrm{~mL}$ round-bottomed flask fitted with magnetic stirrer bar was charged with $5 \mathrm{mmol}$ corresponding tetraalkylammonium or 1,3-dialkyl- or 1,2,3-trialkylimidazolium halide, $5.1 \mathrm{mmol}$ of corresponding borate (19) and $20 \mathrm{~mL}$ of acetone. The mixture was stirred for $2 \mathrm{~h}$ at $25^{\circ} \mathrm{C}$. The solid was filtered and washed by $5 \mathrm{~mL}$ of acetone. The second portion of corresponding salt 1-9 $(1 \mathrm{mmol})$ was added and the resulting mixture was stirred for $2 \mathrm{~h}$ at $25^{\circ} \mathrm{C}$. The solid was filtered and washed by $5 \mathrm{~mL}$ of acetone. The filtrate was evaporated in vacuo. The residue was solved in $5 \mathrm{~mL}$ of dichloromethane (to remove potassium halogenide and excess of potassium polyfluorophenyltrifluoroborate) and filtered. The filtrate was evaporated and product was dried in high vacuo.

An alternative approach for preparation ILs 5 (preparation of 5g). A $25 \mathrm{~mL}$ round-bottomed flask fitted with magnetic stirrer bar and an argon supply equipment was charged with $4.06 \mathrm{~g}$ (26 $\mathrm{mmol})$ of $\mathrm{L}(-)$-isopulegol. $0.86 \mathrm{~g}(21 \mathrm{mmol})$ of $60 \%$ dispersion $\mathrm{NaH}$ was added in portions and then $15 \mathrm{~mL}$ DMF was added. The resulted mixture was stirred at $25{ }^{\circ} \mathrm{C}$ for $1 \mathrm{~h}$ under an atmosphere of argon, and then solution of $\mathrm{BMIM}\left[\mathrm{C}_{6} \mathrm{~F}_{5} \mathrm{BF}_{3}\right]$ (3c, $2.0 \mathrm{~g}, 5 \mathrm{mmol}$ ) in $5 \mathrm{~mL}$ of DMF was added. The flask was put into heating bath at $130{ }^{\circ} \mathrm{C}$ and the reaction mixture was stirred for $5 \mathrm{~h}$ at this temperature. Then it was cooled and $0.5 \mathrm{~mL}$ of water was added. The mixture was evaporated in vacuo and cake was suspended in $10 \mathrm{~mL}$ of $\mathrm{CH}_{2} \mathrm{Cl}_{2}$. The product was isolated by column chromatography (silica 60-200 $\mu \mathrm{m}, d 10 \mathrm{~mm}, h 300$ $\mathrm{mm}$, eluent $\mathrm{CH}_{2} \mathrm{Cl}_{2}$ ). The solution was evaporated in vacuo. The product was dried in high vacuo. $1.84 \mathrm{~g}(68 \%)$ of $5 \mathrm{~g}$ as light brown liquid was prepared.

\section{Conclusions}

This paper presents a new platform for ionic liquids based on pentafluorophenyltrifluoroborate or para-substituted tetrafluorophenyltrifluoroborate anions (Fig. 1). New ionic liquids

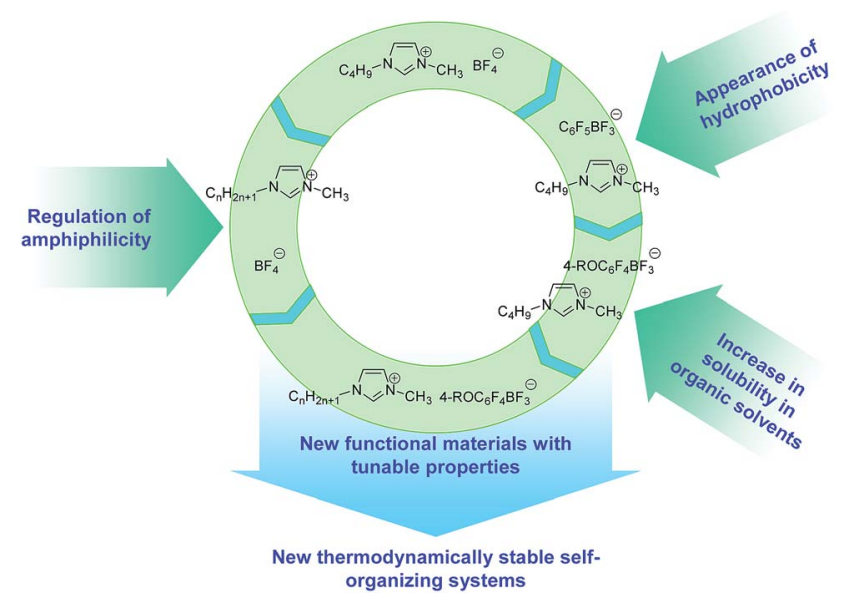

Fig. 1 A place of new ionic liquids, and a generalized representation of their properties.

can be prepared at high yields by ion exchange under mild conditions or directly by nucleophilic substitution of BMIM $\left[\mathrm{C}_{6} \mathrm{~F}_{6} \mathrm{BF}_{3}\right]$ with appropriate reagents.

Fundamental properties of the ionic liquids are determined by the Coulomb interaction and through the formation of hydrogen bonds between hydrogen atom $\mathrm{H}-2$ of the imidazolium cation and fluorine atoms of $\mathrm{BF}_{3}$ moiety. The insertion of a polyfluorinated aromatic ring into the anion changes their behavior in water and organic solvents. This circumstance opens wide possibilities for use ionic liquids obtained in this study in various fields as functional materials.

\section{Acknowledgements}

The works on preparation of novel ionic liquids was conducted within the framework of budget project No. 0303-2016-0007 for Boreskov Institute of Catalysis. The study of the ILs properties have been made with the financial support of the Russian Science Foundation (No. 14-13-00826). The works on preparation of new salts of organotrifluoroborates were supported by the Russian Foundation for Basic Research (grant 16-29-10762).

\section{References}

1 W. Freyland, Coulombic Fluids: Bulk and Interfaces, SpringerVerlag, Berlin Heidelberg, 2011.

2 J. Dupont, Acc. Chem. Res., 2011, 44, 1223-1231.

3 T. Welton, Chem. Rev., 1999, 99, 2071-2084.

4 A. S. Shaplov, E. I. Lozinskaya, P. S. Vlasov, S. M. Morozova, D. Y. Antonov, P. H. Aubert, M. Armand and Y. S. Vygodskii, Electrochim. Acta, 2015, 175, 254-260.

5 I. A. Shkrob and T. W. Marin, J. Phys. Chem. B, 2015, 119, 14766-14779.

6 Y. L. Zhu, Y. Katayama and T. Miura, Electrochem. Solid-State Lett., 2011, 14, D110-D115.

7 A. B. McEwen, H. L. Ngo, K. LeCompte and J. L. Goldman, J. Electrochem. Soc., 1999, 146, 1687-1695. 
8 M. Gazitua, R. A. Tapia, R. Contreras and P. R. Campodonico, New J. Chem., 2014, 38, 2611-2618.

9 A. D. Sawant, D. G. Raut, N. B. Darvatkar and M. M. Salunkhe, Green Chem. Lett. Rev., 2011, 4, 41-54.

10 J. P. Hallett and T. Welton, Chem. Rev., 2011, 111, 3508-3576.

11 H. Zhao, Z. Y. Song, O. Olubajo and J. V. Cowins, Appl. Biochem. Biotechnol., 2010, 162, 13-23.

12 S. Fujita, M. Nishiura and M. Arai, Catal. Lett., 2010, 135, 263-268.

13 S. G. Zlotin and N. N. Makhova, Mendeleev Commun., 2010, 20, 63-71.

14 P. Wasserscheid and T. Welton, Ionic liquids in synthesis, Wiley Online Library, 2008.

15 A. Kamimura, T. Okagawa, N. Oyama, T. Otsuka and M. Yoshimoto, Green Chem., 2012, 14, 2816-2820.

16 I. Newington, J. M. Perez-Arlandis and T. Welton, Org. Lett., 2007, 9, 5247-5250.

17 S. Oppermann, F. Stein and U. Kragl, Appl. Microbiol. Biotechnol., 2011, 89, 493-499.

18 R. K. Goyal, N. S. Jayakumar and M. A. Hashim, J. Hazard. Mater., 2011, 195, 55-61.

19 Y.-X. Wang and X.-J. Cao, Process Biochem., 2012, 47, 896899.

20 E. Brenna, M. Crotti, F. G. Gatti, A. Manfredi, D. Monti, F. Parmeggiani, S. Santangelo and D. Zampieri, ChemCatChem, 2014, 6, 2425-2431.

21 Q. Zhang, S. Zhang and Y. Deng, Green Chem., 2011, 13, 2619-2637.

22 D. Betz, P. Altmann, M. Cokoja, W. A. Herrmann and F. E. Kuhn, Coord. Chem. Rev., 2011, 255, 1518-1540.

23 H. Olivier-Bourbigou, L. Magna and D. Morvan, Appl. Catal., A, 2010, 373, 1-56.

24 M. Sureshkumar and C.-K. Lee, J. Mol. Catal. B: Enzym., 2009, 60, 1-12.

25 X. F. Liu, L. F. Xiao, H. J. Wu, Z. Li, J. Chen and C. U. Xia, Catal. Commun., 2009, 10, 424-427.

26 D. S. Gaikwad, Y. Park and D. M. Pore, Tetrahedron Lett., 2012, 53, 3077-3081.

27 Y. Liu, L. J. Qiao, Y. P. Xiang and R. Guo, Langmuir, 2016, 32, 2582-2590.

28 S. Polarz, S. Landsmann and A. Klaiber, Angew. Chem., Int. Ed., 2014, 53, 946-954.

29 X. Mulet, C. E. Conn, C. Fong, D. F. Kennedy, M. J. Moghaddam and C. J. Drummond, Acc. Chem. Res., 2013, 46, 1497-1505.

30 T. L. Greaves and C. J. Drummond, Chem. Soc. Rev., 2013, 42, 1096-1120.

31 M. E. Mahmoud, Desalination, 2011, 266, 119-127.

32 M. J. Zhou, T. J. Kidd, R. D. Noble and D. L. Gin, Adv. Mater., 2005, 17, 1850-1853.

33 C. S. Consorti, P. A. Z. Suarez, R. F. de Souza, R. A. Burrow, D. H. Farrar, A. J. Lough, W. Loh, L. H. M. da Silva and J. Dupont, J. Phys. Chem. B, 2005, 109, 4341-4349.

34 L. P. Zhang, E. Z. Chen and X. J. Yu, J. Radioanal. Nucl. Chem., 2013, 298, 1055-1063.

35 K. Goossens, K. Lava, C. W. Bielawski and K. Binnemans, Chem. Rev., 2016, 116, 4643-4807.
36 S. Tsuzuki, T. Umecky and H. Matsumoto, in Molten Salts and Ionic Liquids 17, Electrochemical Soc Inc, Pennington, 2010, vol. 33, pp. 685-689.

37 N. V. Ignat'ev, M. Finze, J. A. P. Sprenger, C. Kerpen, E. Bernhardt and H. Willner, J. Fluorine Chem., 2015, 177, 46-54.

38 T. Singh and A. Kumar, J. Phys. Chem. B, 2007, 111, 78437851.

39 Z. B. Zhou, H. Matsumoto and K. Tatsumi, Chem.-Eur. J., 2004, 10, 6581-6591.

40 H. Tokuda, K. Hayamizu, K. Ishii, M. Abu Bin Hasan Susan and M. Watanabe, J. Phys. Chem. B, 2004, 108, 16593-16600.

41 P. A. Z. Suarez, S. Einloft, J. E. L. Dullius, R. F. de Souza and J. Dupont, J. Chim. Phys. Phys.-Chim. Biol., 1998, 95, 16261639.

42 J. Fuller, R. T. Carlin and R. A. Osteryoung, J. Electrochem. Soc., 1997, 144, 3881-3886.

43 P. A. Z. Suarez, J. E. L. Dullius, S. Einloft, R. F. DeSouza and J. Dupont, Polyhedron, 1996, 15, 1217-1219.

44 P. Bonhote, A. P. Dias, N. Papageorgiou, K. Kalyanasundaram and M. Gratzel, Inorg. Chem., 1996, 35, 1168-1178.

45 M. Kermanioryani, M. I. A. Mutalib, Y. Dong, K. C. Lethesh, O. B. Ben Ghanem, K. A. Kurnia, N. F. Aminuddin and J. M. Leveque, J. Chem. Eng. Data, 2016, 61, 2020-2026.

46 E. Gomez, N. Calvar, A. Dominguez and E. A. Macedo, Ind. Eng. Chem. Res., 2013, 52, 2103-2110.

47 D. Rooney, J. Jacquemin and R. L. Gardas, Ionic Liq., 2009, 290, 185-212.

48 C. P. Fredlake, J. M. Crosthwaite, D. G. Hert, S. Aki and J. F. Brennecke, J. Chem. Eng. Data, 2004, 49, 954-964.

49 H. L. Ngo, K. LeCompte, L. Hargens and A. B. McEwen, Thermochim. Acta, 2000, 357, 97-102.

50 H. Xue, R. Verma and J. M. Shreeve, J. Fluorine Chem., 2006, 127, 159-176.

51 N. Nishi, A. Suzuki and T. Kakiuchi, Bull. Chem. Soc. Jpn., 2009, 82, 86-92.

52 Z. B. Zhou, H. Matsumoto and K. Tatsumi, Chem.-Eur. J., 2006, 12, 2196-2212.

53 Z. B. Zhou, H. Matsumoto and K. Tatsumi, Chem.-Eur. J., 2005, 11, 752-766.

54 Z. B. Zhou, M. Takeda and M. Ue, J. Fluorine Chem., 2004, 125, 471-476.

55 K. Iwasaki, K. Yoshii, S. Tsuzuki, T. Tsuda and S. Kuwabata, in Molten Salts and Ionic Liquids 19, Electrochemical Soc Inc, Pennington, 2014, vol. 64, pp. 83-93.

56 M. Shakourian-Fard, Z. Jamshidi, A. Bayat and A. Fattahi, J. Fluorine Chem., 2013, 153, 96-100.

57 S. Tsuzuki, T. Umecky, H. Matsumoto, W. Shinoda and M. Mikami, J. Phys. Chem. B, 2010, 114, 11390-11396.

58 N. Terasawa, S. Tsuzuki, T. Umecky, Y. Saito and H. Matsumoto, Chem. Commun., 2010, 46, 1730-1732.

59 N. V. Ignat'ev, A. Kucheryna, G. Bissky and H. Willner, in Ionic Liquids Iv: Not Just Solvents Anymore, Amer Chemical Soc, Washington, 2007, vol. 975, pp. 320-334.

60 N. Nishi, S. Imakura and T. Kakiuchi, Anal. Chem., 2006, 78, 2726-2731. 
61 G. Singh, G. Singh and T. S. Kang, J. Phys. Chem. B, 2016, 120, 1092-1105.

62 W. W. Xu, T. Wang, N. Cheng, Q. Z. Hu, Y. H. Bi, Y. J. Gong and L. Yu, Langmuir, 2015, 31, 1272-1282.

63 H. Wang, X. Q. Xu, J. F. Shi and G. Xu, Acta Phys.-Chim. Sin., 2013, 29, 525-532.

64 Y. Q. Gu, L. J. Shi, X. Y. Cheng, F. Lu and L. Q. Zheng, Langmuir, 2013, 29, 6213-6220.

65 A. Marciniak, Fluid Phase Equilib., 2010, 294, 213-233.

66 D. Han and K. H. Row, Molecules, 2010, 15, 2405-2426.

67 V. V. Bardin, I. K. Shundrina and H. J. Frohn, J. Fluorine Chem., 2014, 157, 73-78.

68 N. Y. Adonin and V. V. Bardin, Russ. Chem. Rev., 2010, 79, 757-785.

69 H. J. Frohn, H. Franke, P. Fritzen and V. V. Bardin, J. Organomet. Chem., 2000, 598, 127-135.

70 A. Y. Shabalin, N. Y. Adonin, V. V. Bardin, S. A. Prikhod'ko, M. N. Timofeeva, M. V. Bykova and V. N. Parmon, J. Fluorine Chem., 2013, 149, 82-87.

71 V. V. Bardin, I. K. Shundrina and H. J. Frohn, J. Fluorine Chem., 2014, 157, 73-78.

72 M. Kick, P. Keil and A. Konig, Fluid Phase Equilib., 2013, 338, 172-178.

73 Z. B. Zhou, H. Matsumoto and K. Tatsumi, ChemPhysChem, 2005, 6, 1324-1332.

74 D. Bankmann and R. Giernoth, Prog. Nucl. Magn. Reson. Spectrosc., 2007, 51, 63-90.

75 R. D. Falcone, B. Baruah, E. Gaidamauskas, C. D. Rithner, N. M. Correa, J. J. Silber, D. C. Crans and N. E. Levinger, Chem.-Eur. J., 2011, 17, 6837-6846.

76 M. N. Garaga, M. Nayeri and A. Martinelli, J. Mol. Liq., 2015, 210, 169-177.
77 B. A. Marekha, O. N. Kalugin, M. Bria and A. Idrissi, Phys. Chem. Chem. Phys., 2015, 17, 23183-23194.

78 H. Shirota, S. Kakinuma, Y. Itoyama, T. Umecky and T. Takamuku, J. Phys. Chem. B, 2016, 120, 513-526.

79 S. Cha, M. Ao, W. Sung, B. Moon, B. Ahlstrom, P. Johansson, Y. Ouchi and D. Kim, Phys. Chem. Chem. Phys., 2014, 16, 9591-9601.

80 H. Kato, K. Miki, T. Mukai, K. Nishikawa and Y. Koga, J. Phys. Chem. B, 2009, 113, 14754-14760.

81 J. Bowers, C. P. Butts, P. J. Martin, M. C. Vergara-Gutierrez and R. K. Heenan, Langmuir, 2004, 20, 2191-2198.

82 M. Vranes, S. Armakovic, A. Tot, S. Papovic, N. Zec, S. Armakovic, N. Banic, B. Abramovic and S. Gadzuric, J. Chem. Thermodyn., 2016, 93, 164-171.

83 U. Domanska, Pure Appl. Chem., 2005, 77, 543-557.

84 J. B. Harper and R. M. Lynden-Bell, Mol. Phys., 2004, 102, 8594.

85 T. Gutel, C. C. Santini, A. A. H. Padua, B. Fenet, Y. Chauvin, J. N. C. Lopes, F. Bayard, M. F. C. Gomes and A. S. Pensado, J. Phys. Chem. B, 2009, 113, 170-177.

86 T. Shimomura, T. Takamuku and T. Yamaguchi, J. Phys. Chem. B, 2011, 115, 8518-8527.

87 J. D. Holbrey, W. M. Reichert, M. Nieuwenhuyzen, O. Sheppard, C. Hardacre and R. D. Rogers, Chem. Commun., 2003, 476-477.

88 J. F. B. Pereira, L. A. Flores, H. Wang and R. D. Rogers, Chem.-Eur. J., 2015, 20, 15482-15492.

89 N. Y. Adonin, D. E. Babushkin, V. N. Parmon, V. V. Bardin, G. A. Kostin, V. I. Mashukov and H. J. Frohn, Tetrahedron, 2008, 64, 5920-5924. 